\title{
The mediating role of individual-level social capital among worries, mental health and subjective well-being among adults in Hong Kong during the COVID-19 pandemic
}

\author{
Siu-Ming Chan ${ }^{1,2}\left({ }^{10} \cdot\right.$ Gary Ka-Ki Chung $^{1} \cdot$ Yat-Hang Chan ${ }^{1} \cdot$ Jean Woo ${ }^{1,3} \cdot$ Eng Kiong Yeoh ${ }^{1,4}$. \\ Roger Yat-Nork Chung ${ }^{1,3,4}$. Samuel Yeung-Shan Wong ${ }^{1,4} \cdot$ Michael Marmot $^{1,5} \cdot$ Richard Wai-Tong Lee $^{1,3}$. \\ Hung Wong ${ }^{1,6}$
}

Accepted: 13 September 2021

๑) The Author(s), under exclusive licence to Springer Science+Business Media, LLC, part of Springer Nature 2021

\begin{abstract}
The COVID-19 pandemic has substantially induced worries and affected individual mental health and subjective well-being. Nonetheless, a high level of social capital could potentially protect individuals who suffer from mental health problems and thus promote their subjective well-being, especially under the social distancing policies during the pandemic. To this end, based on a random sample of 1053 Hong Kong adults, structural equation modeling was applied to study the path relationships between the worries of COVID-19, social capital, mental health problems, and subjective well-being. The study found that worries during the pandemic were associated with mental health and subjective well-being, through social capital as a mediator. Moreover, social capital exhibited a stronger influence on mental health and subjective well-being in the economically inactive group than in the economically active group. This study highlights the important role of social capital during the COVID-19 pandemic. While Hong Kong's COVID-19 response has primarily focused on disease prevention, it must be noted that social services and mutual-help activities are also crucial for people to withstand the crisis.
\end{abstract}

Keywords COVID-19 $\cdot$ Social capital $\cdot$ Mental health $\cdot$ Subjective well-being $\cdot$ Structural equation modeling $\cdot$ Hong Kong

\section{Introduction}

\section{Worries, Social Capital, Mental Health, and Subjective Well-being}

Siu-Ming Chan

siuming.chan@cityu.edu.hk

1 CUHK Institute of Health Equity, The Chinese University of Hong Kong, The Chinese University of Hong Kong, SAR, Hong Kong, China

2 Department of Social and Behavioural Sciences (Social Work), The City University of Hong Kong, Hong Kong, SAR, China

3 CUHK Institute of Ageing, The Chinese University of Hong Kong, Hong Kong, SAR, China

4 School of Public Health and Primary Care, The Chinese University of Hong Kong, Hong Kong, SAR, China

5 UCL Research Department of Epidemiology and Public Health, UCL Institute of Health Equity, London, UK

6 Department of Social Work, The Chinese University of Hong Kong, Hong Kong, SAR, China
The coronavirus (COVID-19) pandemic sweeping across the world has elevated individuals' worries about the future and about being infected. This has significantly influenced the mental health and subjective well-being (SWB) of every person, not only of those infected, but the general population as well (Alat et al., 2021; Giallonardo et al., 2020; Paredes et al., 2021; Y1ldırım et al., 2021). According to a recent large-scale survey, more than four out of 10 adults in the US reported that their mental health was negatively associated with COVID-19-related worry (Nirmita et al., 2020). Similarly, another study also revealed a negative association between worries of COVID-19 and SWB, which was mediated through future anxiety (Paredes et al., 2021). In China, a recent study demonstrated that during the pandemic, the symptoms of depression and anxiety were negatively associated with quality of life ( $\mathrm{Li}$ et al., 2021). While it was 
argued that the Asian countries was generally outperforming the Western world in controlling the pandemic (Landoni et al., 2020), the stringent lockdown and social distancing measures implemented in these Asian regions also exerted a great adverse impact on the economic situation and psychosocial well-being of individuals, especially for the vulnerable groups (Marmot \& Allen, 2020). For example, a recent telephone survey in Hong Kong found that being deprived had an indirect effect on mental health via worry and job loss/instability under the COVID-19 pandemic (Chung et al., 2021).

As a buffer, a high level of social capital is a common protective factor of mental health and SWB (Hassanzadeh et al., 2016; Nielsen et al., 2015). Social capital generally refers to the trust, social networks, and social connections among individuals and between the individuals and society (Fine, 2001; Woolcock, 2001). Scholars defined social capital as interpersonal trust (Fukuyama, 1995), network, or relationship (Field, 2008; Putnam, 1995). Coleman (1990) linking individuals with social structures, and proposed that certain social structures are more likely to facilitate better social relationships. People can gain higher social capital and benefit from each other in communities or social organizations (Coleman, 1988; Gray \& Simpson, 1998). Moreover, social capital is particularly crucial in rebuilding social ties and infrastructure to withstand catastrophic events (Reininger et al., 2013), and also acts as a psychosocial resource for individuals to cope with the mental distress induced by social crises (Han \& Chung, 2021; Hu et al., 2015; Wong et al., 2019). As illustrated by Hassanzadeh et al. (2016), social capital, socioeconomic status (SES), mental health, and quality of life are interrelated. High levels of social capital and SES were positively associated with both mental health and health-related quality of life.

A growing body of literature suggests that social capital is a key element positively associated with individual mental health and SWB during the COVID-19 pandemic (Almomani et al., 2021; Paolini et al., 2020; Wang et al., 2021; Y1ldırım \& Arslan, 2020). The rapid spread of the virus has forced most governments to implement social distancing and isolation measures, which have unfortunately exerted significant negative impacts on the social capital of individuals (Pitas \& Ehmer, 2020). For example, a study in urban China during the pandemic showed that social capital was negatively associated with depressive symptoms and positively associated with life satisfaction among older adults (Sun \& Lu, 2020). They suggested that older adults had more connections with people and society, which helped them survive the pressure of being isolated during the pandemic. Another study also showed the critically important role of social support in reducing the mental health risks of individuals undergoing social isolation due to the COVID19 regulations (Grey et al., 2020).

On the other hand, individuals from different economic status may face different types or levels of psychological distress due to the pandemic. By economic status, the population is commonly divided into two groups, economically active and inactive populations. The economically active population comprises employed and unemployed people who are seeking employment, whereas the economically inactive group includes students, retired persons, and homemakers. Previous studies showed that the economically inactive group, when compared with the economically active, were at a higher risk of being lonely during the pandemic (Bu et al., 2020; Wong et al., 2020). Pierce et al. (2020) also showed that there was a greater increase in mental distress among the economically active group, compared with the economically inactive. Therefore, people of different economic status appeared to show distinct reactions under the pandemic.

\section{The Context of the Hong Kong Special Administrative Region}

The Hong Kong Special Administrative Region (HKSAR) of the China's government announced their first confirmed COVID-19 case on January 23, 2020, and the total number of infected cases has reached 10,000 after one year, on January 23, 2021. Although the incidence of COVID-19 was relatively low compared with other regions across the world, a number of studies showed that the economic situation and mental health of the general population were deeply affected during the pandemic (Chung et al., 2021; Lau, 2020; Zhao, Wong, Luk, et al., 2020a). For example, a recent study in HKSAR showed that $25.4 \%$ of individuals reported deteriorating mental health since the pandemic started (Choi et al., 2020). Worries about being infected, not having sufficient masks, and not being able to work from home were significantly associated with poor mental health (Choi et al., 2020). Another study also found that depressive symptoms and unhappiness of individuals nearly doubled during the pandemic in HKSAR, compared with three years ago (Zhao, Wong, Wu, et al., 2020b).

In HKSAR, the number of infected cases has increased sharply since November 2020. Along with this, the economic situation worsened. The unemployment and underemployment rate grew from $3.4 \%$ and $1.2 \%$ for the period between November 2019 and January 2020 to $7.0 \%$ and 3.8\% for the period between November 2020 and January 2021, respectively. We hypothesized that the individual's worries over their financial situation and being infected would worsen their social capital, mental health, and SWB. 


\section{Research Gap, Aims of Study, and Research Hypothesis}

As our literature review alluded to above, COVID-19-related worries are generally associated with social capital, mental health, and SWB. However, the mechanism of how worries affect mental health and SWB and the mediating role of social capital among them remain unclear. Moreover, the paths of association among these key elements may vary for social groups with different economic status. This study aims to fill these research gaps by using structural equation modeling (SEM) to examine the relationship among COVID-19-related worries, social capital, mental health, and SWB of the general Hong Kong population. Particularly, through SEM we also aim to investigate the mediating effect of social capital on mental health and SWB. Specifically, this study aims to test the following hypotheses: 1) worries and social capital are significant predictors of mental health and SWB; 2) social capital mediates the association of COVID-19-related worries with mental health and SWB, and 3) the path weightings are significantly different for the economically active and inactive groups.

\section{Methods}

\section{Data and Sample}

Data were collected via telephone survey from a random sample of households in HKSAR. The inclusion criteria for the study were ethnic Chinese residents aged 18 or above. Upon successful contact with a target household, an eligible respondent whose birthday was coming up most recently within each household was invited to participate in the survey. The telephone survey was carried out by experienced interviewers from 11 September to 12 October 2020, between 18:00 and 22:00 on weekdays, weekends, and public holidays. If needed, appointments with suitable subjects were arranged. Among the 12,443 telephone numbers dialed, 10,555 were invalid cases, in which 254 were non-residential lines, 4776 were fax lines/invalid lines, 1308 cut off immediately, and 4217 were non-contacts after three attempts. Among the 1888 answered calls, 28 were terminated mid-way, 59 could not be contacted after three attempts, and 734 refused, resulting in a final sample of 1067 respondents with a $56.5 \%$ response rate. Those cases with missing values in one or more fields $(n=14)$ were excluded in the final analysis; therefore, 1053 observations were analyzed subsequently.

Compared with the general HKSAR population, our respondents were older and more likely to be female. In order to achieve better representativeness, proportional weighting was adopted to reduce the discrepancies between the surveyed adults and the general population with respect to age and sex. The survey data was weighted by the reference population data in mid-2020 obtained from the Census and Statistics Department (C\&SD) of the HKSAR government, prior to performing any analysis.

\section{Measurements}

The questionnaire adopted various measures to assess the worries of COVID-19 pandemic, social capital, mental health, and SWB. Several questions were asked to capture parts of the psychometric properties for each aspect.

COVID-19 Worries Regarding the impact of COVID-19 on the respondents, they were asked whether they experienced four common types of worries since the COVID-19 outbreak. They included worries about being infected (Worry 1), economic activities and livelihood (Worry 2), supply of personal protective equipment (Worry 3 ), and the financial situation of their families (Worry 4). Answers were recorded on a five-point Likert scale. Higher scores represented greater COVID-19-related worries.

Social Capital In this study, social capital was studied at the individual level. The assessment of social capital focused on trust and social connections among people. Three questions were asked to measure the change of social capital since the outbreak of the pandemic, including whether the respondents "can trust anyone" (SC 1), "can ask for help from others" (SC 2), and "are willing to help others easily" (SC 3). Answers were recorded using a five-point Likert scale. Higher scores implied higher levels of social capital.

Mental Health Questions about depressive and anxiety symptoms were asked to assess the mental health situation of respondents. Two validated measurements, the two-item patient health questionnaire (PHQ-2) (MH 1 and MH 2) and the two-item generalized anxiety disorder (GAD-2) screening tool (MH 3 and $\mathrm{MH} \mathrm{4),} \mathrm{were} \mathrm{adopted.} \mathrm{A} \mathrm{four-point} \mathrm{Lik-}$ ert scale was used (not at all, several days, more than half the days, and nearly every day) to investigate the level of depression and anxiety symptoms among the respondents during the pandemic. Higher values referred to a worse mental health status.

Subjective Well-being To assess the level of SWB, a measurement followed the guidelines of the Organisation for Economic Co-operation and Development (OECD) was employed (OECD, 2013). Three questions were asked: "Overall, how satisfied are you with life as a whole these days?" (SWB 1), "Overall, to what extent do you feel the things you do in your life are worthwhile?" (SWB 2), and "How happy did you felt yesterday?" (SWB 3). The 
respondents answered using a scale from zero to 10 , where zero means "not at all satisfied" and 10 means "completely satisfied". Higher scores meant better SWB.

Confounding Variables Information regarding the respondents' age, sex, educational level, social security status, as well as the number of chronic diseases were also collected as confounding factors. In HKSAR, the means-tested comprehensive social security assistance (CSSA) scheme provides a safety net for those who cannot support themselves financially. Anyone receiving the CSSA would be regarded as a recipient of social security.

Economic Status The analysis was divided into two groups, based on the status of economic activities as defined by the C\&SD: the economically active and economically inactive groups. The first group consisted of full-time, part-time employees and self-employed people, as well as unemployed individuals who were looking for work and were available to work. The economically inactive group included retired persons, homemakers, and students.

\section{Analytic Strategy}

The associations among the variables were tested using SEM. SEM is a statistical methodology for investigating the plausibility of theoretical models for explaining the relationships among variables (Hu \& Bentler, 1999). SEM can analyze independent variables, dependent variables, and error terms within a theoretical framework, taking measurement errors into account. It can also address the mediating and moderating effects by estimating the model with interconnecting variables (Hoyle, 2012).

First, items that were theoretically related to the constructs were put into a confirmatory factor analysis for all the latent variables (worries, social capital, mental health problems, and SWB) to eliminate factors with a low-weight loading. The good fit of measurement model indicated that the observed variables have effectively reflected the meanings of the latent variables (Hair et al., 2014; Tabachnick \& Fidell, 2019). This ensured that the constructs in the models were well explained by those observed variables.

Second, the inter-relationship across all the latent variables was tested using SEM based on the overall sample. To measure the mediating effect of social capital, the associations of COVID-19-related worries with mental health and SWB were compared with that of social capital on mental health and SWB. Third, SEM was conducted using a group comparison of economic status (the economically active and economically inactive) to test whether the mediating effects and the strength of their paths are different.

In each SEM model, the regression weight among the variables, the direct and indirect effects on the endogenous variable, and the goodness of fit of the model were obtained. The model for the goodness of fit indices is considered a good fit if the root mean square error of approximation (RMSEA) value is less than 0.08 ( $\mathrm{Hu} \&$ Bentler, 1999). The incremental fit index (IFI), TuckerLewis index (TLI), and comparative fit index (CFI) are satisfied if they are higher than 0.90 (Bentler, 1990). The goodness of fit index (GFI) and adjusted GFI (AGFI) were considered acceptable if the value was larger than 0.80 (Doll et al., 1994; MacCallum \& Hong, 1997). All the models above were adjusted for potential confounders, which were included in the model according to the literature. SPSS and AMOS were employed for statistical analyses. All statistical tests were two-tailed with a significant level of 0.05 .

\section{Results}

\section{Means, Standard Deviation, and Correlations among the Study Variables}

The means and standard deviations (SDs) of the key variables are listed in Table 1. The difference of key variables between the economically active and inactive groups were compared using ANOVA (Table 1). The correlations among the confounding variables and observed variables used in the construction of COVID-19-related worries, social capital, mental health outcomes, and SWB are presented in Table 2. Pearson's correlation was used to analyze the correlation among the variables (Table 2).

\section{Measurement Model}

The measurement models of the latent variables have been verified before being merged into a structural equation model. Confirmatory factor analysis (CFA) was used to examine whether the observed data represented the meanings of the constructs (Hoyle, 2012). The minimum acceptable loading of each factor of the construct is 0.30 (Hair et al., 2014; Tabachnick \& Fidell, 2019). The factors' loadings of the observed variables for worries, social capital, mental health outcomes, and SWB ranged from 0.43 to $0.92,0.84$ to $0.93,0.73$ to 0.85 , and 0.57 to 0.95 , respectively. These results indicated that the observed variables have effectively reflected the meanings of the latent variables. The Cronbach's alpha for the measured items of COVID-19-related worries, social capital, mental health outcomes, and SWB were $0.80,0.93,0.89$, and 0.81 , respectively. They represented high levels of reliability for the measurements. 
Table 1 Descriptive result and ANOVA result of economically active and economically inactive group

\begin{tabular}{|c|c|c|c|c|}
\hline & $\begin{array}{l}\text { Overall population } \\
\text { Means (SD) }\end{array}$ & $\begin{array}{l}\text { Economically active } \\
\text { Means (SD) }\end{array}$ & $\begin{array}{l}\text { Economically inactive } \\
\text { Means (SD) }\end{array}$ & $\mathrm{p}$ value \\
\hline Worry1: being infected & $3.24(1.17)$ & $3.32(1.16)$ & $3.17(1.18)$ & .042 \\
\hline Worry2: economic activity/livelihood & $3.11(1.20)$ & $3.23(1.18)$ & $2.97(1.21)$ & .000 \\
\hline Worry3: personal savings & $2.89(1.12)$ & $3.00(1.13)$ & $2.78(1.10)$ & .001 \\
\hline Worry4: financial situation of my family & $2.72(1.23)$ & $2.81(1.24)$ & $2.61(1.21)$ & .007 \\
\hline $\mathrm{SC} 1$ : trust anyone & $4.11(0.86)$ & $4.07(0.87)$ & $4.15(0.85)$ & .113 \\
\hline SC2: ask for help from others & $4.06(0.90)$ & $4.01(0.92)$ & $4.12(0.87)$ & .050 \\
\hline SC3: willing to help others & $4.18(0.83)$ & $4.14(0.86)$ & $4.23(0.80)$ & .063 \\
\hline MH1: little interest or pleasure in doing things & $1.17(0.47)$ & $1.20(0.54)$ & $1.13(0.38)$ & .011 \\
\hline MH2: feeling down, depressed, or hopeless & $1.17(0.48)$ & $1.21(0.56)$ & $1.12(0.38)$ & .004 \\
\hline MH3: feeling nervous, anxious or on edge & $1.23(0.51)$ & $1.29(0.57)$ & $1.18(0.44)$ & .001 \\
\hline MH4: not being able to stop or control worrying & $1.14(0.45)$ & $1.19(0.51)$ & $1.10(0.38)$ & .002 \\
\hline SWB1: happiness & $6.64(1.57)$ & $6.32(1.56)$ & $6.98(1.50)$ & .000 \\
\hline SWB2: life is worthwhile & $7.08(1.56)$ & $7.00(1.60)$ & $7.16(1.51)$ & .111 \\
\hline SWB3: life satisfaction & $6.48(1.65)$ & $6.18(1.63)$ & $6.80(1.61)$ & .000 \\
\hline
\end{tabular}

\section{Overall SEM Model}

In the overall model with the total sample, the model demonstrated a good model fit $(\chi / \mathrm{df}=4.32, \mathrm{p}<0.001$; RMSEA $=0.040, \mathrm{IFI}=0.942, \mathrm{TLI}=0.915, \mathrm{CFI}=0.941$, $\mathrm{GFI}=0.928)$. The chi-square and $\mathrm{p}$ value can be overlooked because of the relatively large sample size (>200) (Bollen \& Long, 1993; Byrne, 2001; Maruyama, 1998). All the indexes were of a good standard for adoption, indicating that the overall model was good. The standardized results of the structural model are shown in Fig. 1 and Table 3. For simplicity, the figure only shows the paths of association among the explanatory variables, the mediating variables, and the dependent variable. The path diagram of the measurement models is omitted.

In the overall model, the exogenous variables explained approximately $41 \%$ of the variance of SWB. All the paths among COVID-19-related worries, social capital, mental health outcomes, and SWB were statistically significant, except the path from social capital to SWB. COVID19-related worries showed a significant and strong direct influence on social capital $(\beta=-0.28, p<0.001)$, mental health outcomes ( $\beta=0.25, \mathrm{p}<0.001)$, and SWB $(\beta=-0.23$, $\mathrm{p}<0.001$ ). Additionally, the indirect effect of COVID-19-related worries on mental health problems $(\beta=0.03, p=0.030)$ and SWB $(\beta=-0.15, \mathrm{p}=0.010)$ were also statistically significant (Table 4).

On the other hand, social capital negatively affected mental health $(\beta=-0.09, p=0.030)$, which then further exerted a strong negative influence on SWB $(\beta=-0.47, p=0.010)$. Although the direct effect of social capital on SWB was not statistically significant as mentioned above, the total effect of social capital on SWB was statistically significant $(\beta=0.09$, $\mathrm{p}=0.010)$ (Table 4). Overall, the results indicated that COVID-19-related worries had significantly strong negative effects on social capital, mental health, and SWB. In addition, social capital mediated the influence of COVID19-related worries on mental health and SWB, though the effect was not strong.

\section{Group Comparison}

The sample of respondents was divided into two groups: the economically active and economically inactive, with both models providing a good fit. For comparison, the models explained $45 \%$ and $35 \%$ of SWB for the economically active and economically inactive groups, respectively.

For the economically active group, the COVID-19-related worries showed a significant and strong direct influence on social capital $(\beta=-0.21, \mathrm{p}<0.001)$, mental health $(\beta=0.32$, $\mathrm{p}<0.001)$, and SWB $(\beta=-0.31, \mathrm{p}<0.001)$ (Table 3). However, the effect of social capital on mental health and SWB was not significant. The indirect effect from COVID-19-related worries to SWB was mediated by mental health, but not by social capital. This result demonstrated that the meditating effect of social capital was weak and non-significant in the economically active group.

For the economically inactive group, the COVID-19-related worries revealed a strong negative direct effect on social capital $(\beta=-0.39, p<0.001)$ and SWB $(\beta=-0.16$, $\mathrm{p}<0.001$ ), but showed non-significant direct influence on mental health $(\beta=-0.09, p=0.107)$. On the other hand, social capital strongly affected mental health $(\beta=-0.27$, $\mathrm{p}<0.001$ ), which was found to have further direct effect on SWB $(\beta=-0.46, p<0.001)$. The indirect effect of social capital on SWB was the largest among the three models 


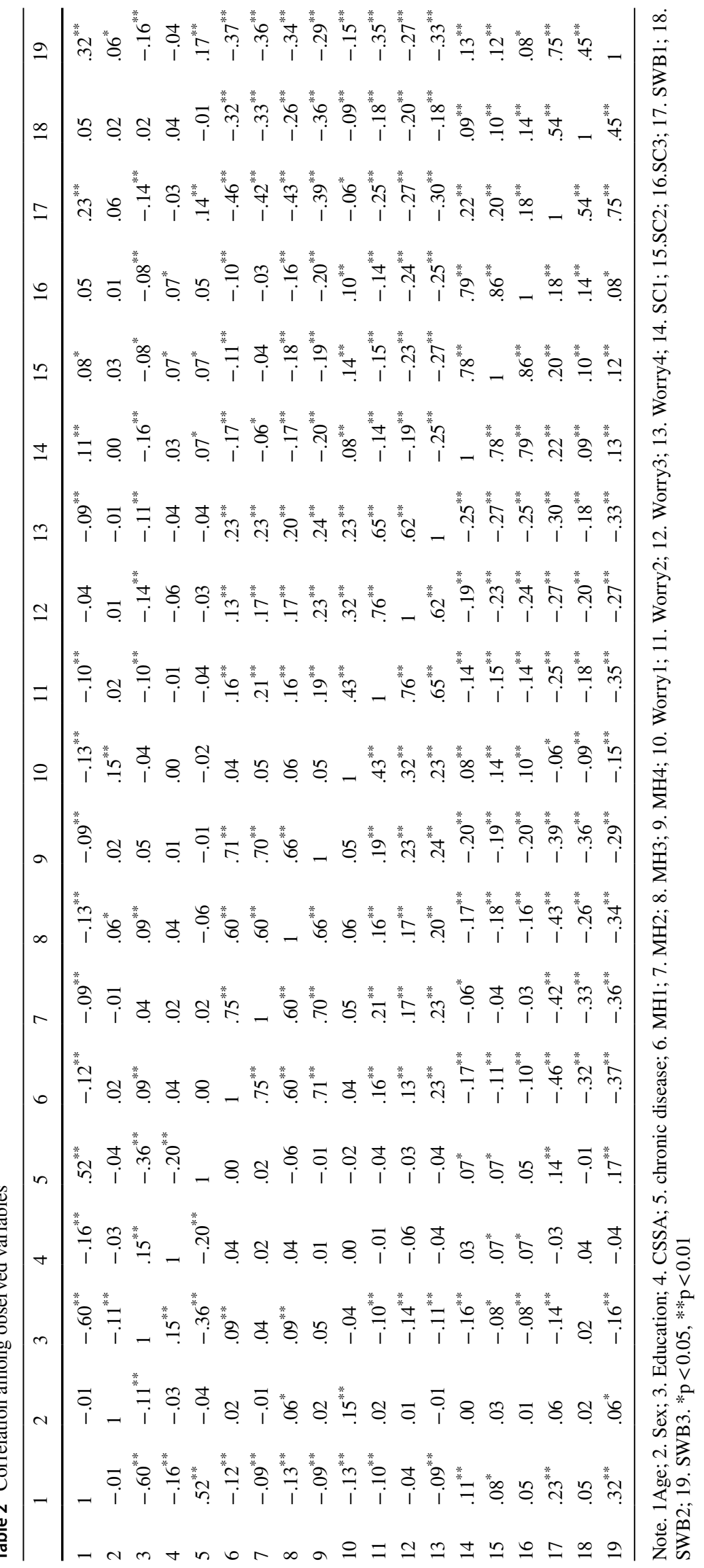


Fig. 1 SEM Model. a: overall; b: economically active; c: economically inactive. ${ }^{*} \mathrm{p}<.05$, $* * \mathrm{p}<.01, * * * \mathrm{p}<.001$. Source: Table 4

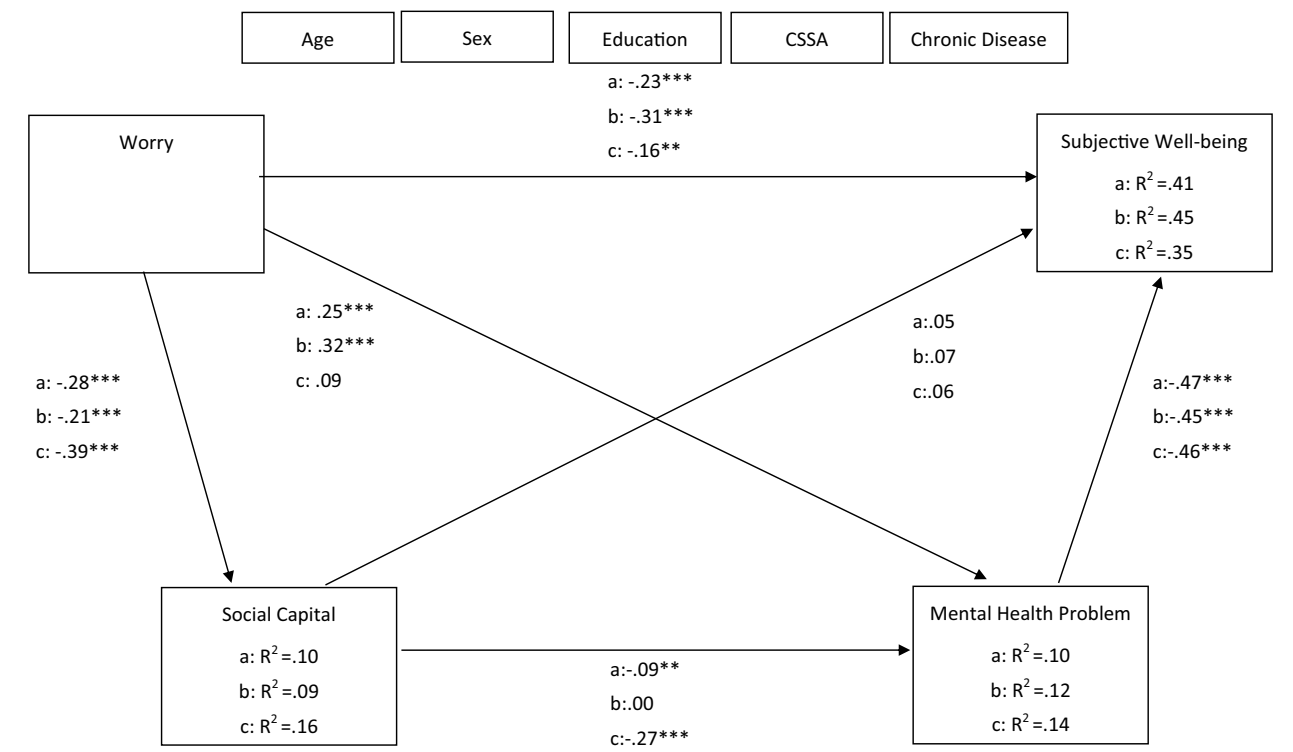

Table 3 Path coefficients, standard errors, and critical ratios of the comparison model

\begin{tabular}{|c|c|c|c|c|c|c|c|c|c|c|c|}
\hline & & & \multicolumn{3}{|l|}{ Overall } & \multicolumn{3}{|c|}{ Economic active } & \multicolumn{3}{|c|}{ Economic inactive } \\
\hline & & & $\beta$ & S.E. & C.R. & $\beta$ & S.E. & C.R. & $\beta$ & S.E. & C.R. \\
\hline Social Capital & $\leftarrow$ & Worry & $-.284 * * *$ & .077 & -6.577 & $-.206^{* * *}$ & .084 & -3.928 & $-.388 * * *$ & .175 & -4.744 \\
\hline Mental Health Problem & $\leftarrow$ & Worry & $.255^{* * *}$ & .043 & 5.819 & $.318 * * *$ & .062 & 5.242 & .091 & .054 & 1.614 \\
\hline Mental Health Problem & $\leftarrow$ & Social Capital & $-.091 * *$ & .019 & -2.620 & -.003 & .030 & -.063 & $-.273 * * *$ & .024 & -5.148 \\
\hline Subjective Well-being & $\leftarrow$ & Worry & $-.227 * * *$ & .129 & -5.836 & $-.311 * * *$ & .169 & -5.481 & $-.156^{* *}$ & .207 & -2.812 \\
\hline Subjective Well-being & $\leftarrow$ & Social Capital & .050 & .055 & 1.710 & .071 & .073 & 1.794 & .055 & .084 & 1.143 \\
\hline Subjective Well-being & $\leftarrow$ & Mental Health Problem & $-.465 * * *$ & .119 & -13.174 & $-.449 * * *$ & .141 & -9.272 & $-.462 * * *$ & .209 & -8.525 \\
\hline
\end{tabular}

$\beta$ Standardized Coefficients, S. E. Standard Error, C.R. Critical Ratio, ${ }^{*} \mathrm{p}<0.05, * * \mathrm{p}<0.01, * * * \mathrm{p}<0.001$

$(\beta=0.13, \mathrm{p}<0.001)$ (Table 4$)$. The results showed social capital's crucial role in mediating the influence of COVID19-related worries on mental health, and SWB in the economically inactive group.

\section{Discussion and Conclusion}

This study examined the mechanism behinds the associations of COVID-19 related worries with social capital, mental health, and SWB using SEM. We found that COVID19-related worries were generally a significant predictor of SWB and mental health problems, especially in the economically active group. On the other hand, social capital is not a predictor of SWB in the economically active group, but had a significant indirect effect on SWB through mental health outcomes in the overall sample and specifically in the economically inactive group. These results partly supported our first hypothesis, where worries and social capital were significant predictors of mental health outcomes and SWB.
With regard to our second hypothesis, we found that social capital mediated the association among COVID-19-related worries, mental health problems, and SWB, in the overall sample and specifically in the economically inactive group. However, the influence of social capital on mental health and SWB in the economically active group was not significant. Therefore, our second hypothesis was only partly supported. Last, the path relationships among the variables were different, in terms of significance and weighting, between the economically active and inactive groups, which supported our third hypothesis.

COVID-19-related worries showed a significant association with mental health and were found to have a strong negative effect on social capital and SWB in all models. This result echoed most of the previous literature that worries about being infected and one's financial situation created an extra psychological burden on individuals (Giallonardo et al., 2020; Paredes et al., 2021). In addition to those results, this study further revealed that the association of COVID-19-related worries with SWB in the 
Table 4 Standardized total, direct and indirect effect of all models

\begin{tabular}{|c|c|c|c|c|c|c|c|c|c|}
\hline & \multicolumn{3}{|l|}{ Overall } & \multicolumn{3}{|c|}{ Economic active } & \multicolumn{3}{|c|}{ Economic inactive } \\
\hline & Worry & Social Capital & $\begin{array}{l}\text { Mental } \\
\text { Health } \\
\text { Problem }\end{array}$ & Worry & Social Capital & $\begin{array}{l}\text { Mental } \\
\text { Health } \\
\text { Problem }\end{array}$ & Worry & Social Capital & $\begin{array}{l}\text { Mental } \\
\text { Health } \\
\text { Problem }\end{array}$ \\
\hline \multicolumn{10}{|l|}{ Total Effect } \\
\hline Social Capital & $-.284 * * *$ & .000 & .000 & $-.206 * * *$ & .000 & .000 & $-.388 * *$ & .000 & .000 \\
\hline $\begin{array}{l}\text { Mental Health } \\
\text { Problem }\end{array}$ & $.281 * * *$ & $-.091^{*}$ & .000 & $.319 * * *$ & -.003 & .000 & $.197 * *$ & $-.273 * * *$ & .000 \\
\hline $\begin{array}{l}\text { Subjective Well- } \\
\text { being }\end{array}$ & $-.372 * * *$ & $.093 * *$ & $-.465 * * *$ & $-.469 * * *$ & .072 & $-.449 * * *$ & $-.269 * * *$ & $.181 * *$ & $-.462 * * *$ \\
\hline \multicolumn{10}{|l|}{ Direct Effect } \\
\hline Social Capital & $-.284 * * *$ & .000 & .000 & $-.206 * * *$ & .000 & .000 & $-.388^{* *}$ & .000 & .000 \\
\hline $\begin{array}{l}\text { Mental Health } \\
\text { Problem }\end{array}$ & $.255^{* * *}$ & $-.091^{*}$ & .000 & $.318 * * *$ & -.003 & .000 & .091 & $-.273 * * *$ & .000 \\
\hline $\begin{array}{l}\text { Subjective Well- } \\
\text { being }\end{array}$ & $-.227 * * *$ & .050 & $-.465^{* * *}$ & $-.311 * *$ & .071 & $-.449 * * *$ & $-.156^{* * *}$ & .055 & $-.462 * * *$ \\
\hline \multicolumn{10}{|l|}{ Indirect Effect } \\
\hline Social Capital & .000 & .000 & .000 & .000 & .000 & .000 & .000 & .000 & .000 \\
\hline $\begin{array}{l}\text { Mental Health } \\
\text { Problem }\end{array}$ & $.026^{*}$ & .000 & .000 & .001 & .000 & .000 & $.106^{* * *}$ & .000 & .000 \\
\hline $\begin{array}{l}\text { Subjective Well- } \\
\text { being }\end{array}$ & $-.145 * * *$ & $.042 *$ & .000 & $-.158 * * *$ & .001 & .000 & $-.112 * * *$ & $.126 * * *$ & .000 \\
\hline
\end{tabular}

$* \mathrm{p}<0.05, * * \mathrm{p}<0.01, * * * \mathrm{p}<0.001$

economically active group was much stronger than that in the economically inactive group. One possible explanation is that the economic downturn and the rise of unemployment increased the psychological distress of the economically active group. This is also consistent with a recent study in HKSAR showing that being deprived had an indirect effect on mental health through worry and job loss/ instability (Chung et al., 2021). Although the influence of COVID-19-related worries on mental health problems and SWB is more direct in the economically active group than in the economically inactive group, the mediating effect of social capital was not significant in the economically active group. It is reasonable because employment and financial stability were more crucial than social support for economically active individuals. The HKSAR government launched the Employment Support Scheme since 2020 to tackle the employment problems during the pandemic and spent more than 90 billion Hong Kong dollars on it. (HKSAR government, 2021). Still, the worries about livelihood and personal savings remain high among the economically active cases. Through policy interventions, unemployment assistance schemes offering monthly subsidies to the unemployed may help them sustain themselves during such periods. Additionally, enhancing the current employee retraining programs and increasing the allowance could possibly provide more stable financial support and relieve the worries of the unemployed and underemployed.

On the other hand, our findings highlighted the importance of social support and social connection during the pandemic to enhance mental health and SWB in the economically inactive group. The social distancing policy was implemented by the government to protect people from infections; however, the negative effect of social isolation on psychological well-being was not a priority at the time of the outbreak. As a strategy to tackle COVID-19, the HKSAR government mainly focused on disease prevention and outbreak control, but less on social and mental health support. Social services and mutual-help activities are crucial for people to withstand the crisis due to the pandemic. To enhance social inclusion and strengthen the social capital in the community, a substantial increase in the amount of social welfare funding after the outbreak has already been suggested. This aims to promote mutual assistance and community resilience through non-governmental organizations and social workers. However, since the risk of suffering from mental disorders is also growing under the pandemic (Choi et al., 2020), it is suggested that boosting the resources on mental health services would also help people with potential mental health problems resist the extra psychological burden induced by the pandemic. Another point to be highlighted for 
the economically inactive group is that the influence of worries on mental health and SWB was relatively weak. One possible explanation was the older adults, most of whom were economically inactive, coped better with worries compared with younger adults, as previous studies supported that older adults had a high resilience towards social crisis (Brown et al., 2021; Cohen, 2006; MorrowHowell et al., 2020). The resilience and coping mechanisms of individuals under the pandemic warrants further in-depth studies in the future.

There are several limitations in the current study. First, since this study was based on a cross-sectional survey, the relationships among the variables were not causal and conclusions about causal effects cannot be inferred. Caution should be taken when applying cross-sectional results for further studies on related topic. Second, although several confounding variables were considered in the SEM models, not all risk factors of mental health and SWB, such as a family history of mental illness or life events, were controlled in the analysis due to limited data availability. Third, as the assessment of mental health problems relied on self-reporting, the results may be subject to recall bias. Fourth, the survey was conducted through telephone interviews which may limit the completeness and amount of data collected. While the use of a brief set of measures could be a strength for conducting short telephone surveys, they may not capture all the psychometric properties of the measurement tools. Nevertheless, this study was based on a random sample weighted with age and sex, giving a good representation of the Hong Kong general adult population. Moreover, the SEM approach allowed the operationalization of the constructs with different observed variables and provided a good estimation of the relationships among the key variables.

In conclusion, this study highlighted the important role of social capital during the pandemic. Even in a region where the incidence of COVID-19 is relatively low, people's mental health and well-being could still be affected without being infected, due to genuine worries and social distancing. It is therefore important for policymakers to go beyond the utilitarian nature of disease prevention and health maximization when devising strategies for COVID19. In addition to financial support for families in need, building social capital and social relationship are also crucial in protecting people's mental health and well-being during the pandemic, and the social determinants of health also need to be adequately considered.

Acknowledgements We would like to thank all staff at the Chinese University of Hong Kong Institute of Health Equity for their support in this research project. The second author, Gary K.K. Chung, acknowledges the Research Grant Council for its support over his Postdoctoral Fellowship (Ref. No.: PDFS2122-4H02).
Data Availability Statements The datasets generated or analysed during this study are included in this published article (and its supplementary information files).

Author's Contribution SC, as the first author, was responsible for literature search, study design, data analysis, data interpretation, and contributed significantly to the write-up of the manuscript. GKC and YC have verified the underlying data, and contributed to the literature search, data interpretation, and the write-up of the manuscript. JW, EKY, RYC, SYW, MM, and RWL were responsible for data interpretation, the write-up and critical appraisal of the manuscript. WH oversaw the study and was responsible for the conceptualization of the study, study design, data interpretation, and led the write-up of the manuscript. All authors had full access to all the data in the study and accept responsibility to submit for publication.

Funding The work was supported by a research project grant from the Chinese University of Hong Kong Institute of Health Equity, which was funded by the Vice-Chancellor's Discretionary Fund of the Chinese University of Hong Kong (Project Ref No.: 136604080).

\section{Declarations}

Ethics Approval This study was approved by Joint Chinese University of Hong Kong-New Territories East Cluster Clinical Research Ethics Committee in August 2020.

Conflict of Interest The authors have no relevant financial or non-financial interests to disclose.

Consent to Participate Informed consent was obtained from all individual participants included in the study.

\section{References}

Alat, P., Das, S. S., Arora, A., \& Jha, A. K. (2021). Mental health during COVID-19 lockdown in India: Role of psychological capital and internal locus of control. Current Psychology, 1-13. https:// doi.org/10.1007/s12144-021-01516-X

Almomani, E. Y., Qablan, A. M., Almomany, A. M., \& Atrooz, F. Y. (2021). The coping strategies followed by university students to mitigate the COVID-19 quarantine psychological impact. Current Psychology, 1-10. https://doi.org/10.1007/s12144-021-01833-1.

Bentler, P. M. (1990). Comparative fit indexes in structural models. Psychological Bulletin, 107(2), 238-246. https://doi.org/10.1037/ 0033-2909.107.2.238

Bollen, K. A., \& Long, S. J. (1993). Testing structural equation models. SAGE Publications.

Brown, L., Mossabir, R., Harrison, N., Brundle, C., Smith, J., \& Clegg, A. (2021). Life in lockdown: A telephone survey to investigate the impact of COVID-19 lockdown measures on the lives of older people ( $\geq 75$ years). Age and Ageing, 50(2), 341-346. https://doi. org/10.1093/ageing/afaa255

Bu, F., Steptoe, A., \& Fancourt, D. (2020). Loneliness during lockdown: Trajectories and predictors during the COVID-19 pandemic in 35,712 adults in the UK. In medRxiv (p. 2020.05.29.20116657). medRxiv. https://doi.org/10.1101/2020.05.29.20116657

Byrne, B. M. (2001). Structural Equation Modeling With AMOS,EQS, and LISREL: Comparative Approaches to Testing for the Factorial Validity of a Measuring Instrument. International Journal of Testing, 1(1), 55-86. https://doi.org/10.1207/S15327574IJT0101 
Choi, E. P. H., Hui, B. P. H., \& Wan, E. Y. F. (2020). Depression and anxiety in Hong Kong during covid-19. International Journal of Environmental Research and Public Health, 17(10). https://doi. org/10.3390/ijerph17103740

Chung, R. Y. N., Chung, G. K. K., Marmot, M., Allen, J., Chan, D., Goldblatt, P., Wong, H., Lai, E., Woo, J., Yeoh, E. K., \& Wong, S. Y. S. (2021). COVID-19 related health inequality exists even in a city where disease incidence is relatively low: A telephone survey in Hong Kong. Journal of Epidemiology and Community Health, 0, 1-8. https://doi.org/10.1136/jech-2020-215392.

Cohen, G. D. (2006). The mature mind: The positive power of the aging brain. Basic Books.

Coleman, J. S. (1988). Social Capital in the Creation of human capital. American Journal of Sociology, 94, S95-S120. https://doi.org/ $10.1086 / 228943$

Coleman, J. S. (1990). Foundations of social theory. Harvard University Press.

Doll, W. J., Xia, W., \& Torkzadeh, G. (1994). A confirmatory factor analysis of the end-user computing satisfaction instrument. MIS Quarterly: Management Information Systems, 18(4), 453-460. https://doi.org/10.2307/249524

Field, J. (2008). Social Capital. Routledge.

Fine, B. (2001). Social capital versus social theory political economy and social science at the turn of the millenium. Routledge.

Fukuyama, F. (1995). Trust: The social virtues and the creation of prosperity. Free Press.

Giallonardo, V., Sampogna, G., Del Vecchio, V., Luciano, M., Albert, U., Carmassi, C., Carrà, G., Cirulli, F., Dell'Osso, B., Nanni, M. G., Pompili, M., Sani, G., Tortorella, A., Volpe, U., \& Fiorillo, A. (2020). The impact of quarantine and physical distancing following covid-19 on mental health: Study protocol of a multicentric italian population trial. Frontiers in Psychiatry, 11. https://doi.org/ 10.3389/fpsyt.2020.00533

Gray, M., \& Simpson, B. (1998). Developmental social work education: A field example. International Social Work, 41(2), 227-237. https://doi.org/10.1177/002087289804100209

Grey, I., Arora, T., Thomas, J., Saneh, A., Tomhe, P., \& Abi-Habib, R. (2020). The role of perceived social support on depression and sleep during the COVID-19 pandemic. Psychiatry Research, 293, 113452. https://doi.org/10.1016/j.psychres.2020.113452

Hair, J. F., Black, W. C., Babin, B. J., \& Anderson, R. E. (2014). Multivariate data analysis (7th ed.). Pearson Education.

Han, Y., \& Chung, R. Y.-N. (2021). Are both individual-level and county-level social capital associated with individual health? A serial cross-sectional analysis in China, 2010-2015. BMJ Open, 11(8), e044616. https://doi.org/10.1136/bmjopen-2020-044616

Hassanzadeh, J., Asadi-Lari, M., Baghbanian, A., Ghaem, H., Kassani, A., \& Rezaianzadeh, A. (2016). Association between social capital, health-related quality of life, and mental health: A structuralequation modeling approach. Croatian Medical Journal, 57(1), 58-65. https://doi.org/10.3325/cmj.2016.57.58

HKSAR government. (2021). The HKSAR government press release (unemployment problem). https://www.info.gov.hk/gia/general/ 202103/17/P2021031700381.htm?fontSize $=1$

Hoyle, R. H. (2012). Handbook of structural equation modeling. The Guilford Press.

Hu, L. T., \& Bentler, P. M. (1999). Cutoff criteria for fit indexes in covariance structure analysis: Conventional criteria versus new alternatives. Structural Equation Modeling, 6(1), 1-55. https:// doi.org/10.1080/10705519909540118

Hu, S., Tan, H., Cofie, R., Zhou, J., Yang, T., Tang, X., \& Liu, A. (2015). Recovery from post-traumatic stress disorder after a flood in China: A 13-year follow-up and its prediction by degree of collective action. BMC Public Health, 15(1), 1-7. https://doi.org/10. 1186/s12889-015-2009-6
Landoni, G., Maimeri, N., Fedrizzi, M., Fresilli, S., Kuzovlev, A., Likhvantsev, V., Nardelli, P., \& Zangrillo, A. (2020). Why are Asian countries outperforming the Western world in controlling COVID-19 pandemic? 115(1), 70-72. https://doi.org/10.1080/ 20477724.2020.1850982.

Lau, P. Y. F. (2020). Fighting COVID-19: Social capital and community mobilisation in Hong Kong. International Journal of Sociology and Social Policy, 40(9-10), 1059-1067. https://doi.org/10. 1108/IJSSP-08-2020-0377

Li, W., Zhao, N., Yan, X., Zou, S., Wang, H., Li, Y., Xu, X., Du, X., Zhang, L., Zhang, Q., Cheung, T., Ungvari, G. S., Ng, C. H., \& Xiang, Y.-T. (2021). The prevalence of depressive and anxiety symptoms and their associations with quality of life among clinically stable older patients with psychiatric disorders during the COVID-19 pandemic. Translational Psychiatry, 11(1), 75. https:// doi.org/10.1038/s41398-021-01196-y

MacCallum, R. C., \& Hong, S. (1997). Power analysis in covariance structure modeling using GFI and AGFI. Multivariate Behavioral Research, 32(2), 193-210. https://doi.org/10.1207/s15327906m br3202 5

Marmot, M., \& Allen, J. (2020). COVID-19: Exposing and amplifying inequalities. Journal of Epidemiology and Community Health, 74(9), 681-682. https://doi.org/10.1136/JECH-2020-214720

Maruyama, G. M. (1998). Basics of structural equation modeling. SAGE Publications.

Morrow-Howell, N., Galucia, N., \& Swinford, E. (2020). Recovering from the COVID-19 pandemic: A focus on older adults. Journal of Aging and Social Policy, 32(4-5), 526-535. https://doi.org/10. 1080/08959420.2020.1759758

Nielsen, L., Koushede, V., Vinther-Larsen, M., Bendtsen, P., Ersbøll, A. K., Due, P., \& Holstein, B. E. (2015). Does school social capital modify socioeconomic inequality in mental health? A multilevel analysis in Danish schools. Social Science and Medicine, 140, 35-43. https://doi.org/10.1016/j.socscimed.2015.07.002

Nirmita, P., Rabah, K., Cynthia, C., \& Rachel, G. (2020). The Implications of COVID-19 for Mental Health and Substance Use. https:// www.kff.org/health-reform/issue-brief/the-implications-of-covid19-for-mental-health-and-substance-use/view/print/

OECD. (2013). OECD Guidelines on Measuring Subjective Well-being. https://doi.org/10.1787/9789264191655-en

Paolini, D., Maricchiolo, F., Pacilli, M. G., \& Pagliaro, S. (2020). COVID-19 lockdown in Italy: The role of social identification and social and political trust on well-being and distress. Current Psychology, 1-8. https://doi.org/10.1007/s12144-020-01141-0.

Paredes, M. R., Apaolaza, V., Fernandez-Robin, C., Hartmann, P., \& Yañez-Martinez, D. (2021). The impact of the COVID-19 pandemic on subjective mental well-being: The interplay of perceived threat, future anxiety and resilience. Personality and Individual Differences, 170, 110455. https://doi.org/10.1016/j.paid.2020. 110455

Pierce, M., Hope, H., Ford, T., Hatch, S., Hotopf, M., John, A., Kontopantelis, E., Webb, R., Wessely, S., McManus, S., \& Abel, K. M. (2020). Mental health before and during the COVID-19 pandemic: A longitudinal probability sample survey of the UK population. The Lancet Psychiatry, 7(10), 883-892. https://doi.org/10.1016/ S2215-0366(20)30308-4

Pitas, N., \& Ehmer, C. (2020). Social Capital in the Response to COVID-19. American Journal of Health Promotion, 34(8), 942944. https://doi.org/10.1177/0890117120924531

Putnam, R. D. (1995). Bowling alone: America's declining social capital. Journal of Democracy, 6(1), 65-78. https://doi.org/10.1353/ jod.1995.0002

Reininger, B. M., Rahbar, M. H., Lee, M. J., Chen, Z., Alam, S. R., Pope, J., \& Adams, B. (2013). Social capital and disaster preparedness among low income Mexican Americans in a disaster prone 
area. Social Science and Medicine, 83, 50-60. https://doi.org/10. 1016/j.socscimed.2013.01.037

Sun, Q., \& Lu, N. (2020). Social capital and mental health among older adults living in urban China in the context of COVID-19 pandemic. International Journal of Environmental Research and Public Health, 17(21), 7947. https://doi.org/10.3390/ijerph1721 7947

Tabachnick, B. G., \& Fidell, L. S. (2019). Using multivariate statistics (7th ed.). Pearson Education.

Wang, Y., Ariyo, T., Liu, H., \& Ma, C. (2021). Does psychosocial support buffer the effect of COVID-19 related stressors on mental health among Chinese during quarantine? Current psychology, 1-11. https://doi.org/10.1007/s12144-021-01663-1.

Wong, H., Huang, Y., Fu, Y., \& Zhang, Y. (2019). Impacts of structural social capital and cognitive social capital on the psychological status of survivors of the Yaan earthquake. Applied Research in Quality of Life, 14(5), 1411-1433. https://doi.org/10.1007/ s11482-018-9661-9

Wong, S. Y. S., Zhang, D., Sit, R. W. S., Yip, B. H. K., Chung, R. Y.-N., Wong, C. K. M., Chan, D. C. C., Sun, W., Kwok, K. O., \& Mercer, S. W. (2020). Impact of COVID-19 on loneliness, mental health, and health service utilisation: A prospective cohort study of older adults with multimorbidity in primary care. British Journal of General Practice, 70(700), E817-E824. https://doi.org/10. 3399/BJGP20X713021

Woolcock, M. (2001). The place of social Capital in Understanding Social and Economic Outcomes. Canadian Journal of Policy Research, 2(1), 11-17.
Yıldırım, M., \& Arslan, G. (2020). Exploring the associations between resilience, dispositional hope, preventive behaviours, subjective well-being, and psychological health among adults during early stage of COVID-19. Current Psychology, 1-11. https://doi.org/10. 1007/s12144-020-01177-2.

Yıldırım, M., Arslan, G., \& Wong, P. T. P. (2021). Meaningful living, resilience, affective balance, and psychological health problems among Turkish young adults during coronavirus pandemic. Current Psychology, 1-12. https://doi.org/10.1007/ s12144-020-01244-8

Zhao, S. Z., Wong, J. Y. H., Luk, T. T., Wai, A. K. C., Lam, T. H., \& Wang, M. P. (2020a). Mental health crisis under COVID-19 pandemic in Hong Kong, China. International Journal of Infectious Diseases, 100, 431-433. https://doi.org/10.1016/j.ijid.2020. 09.030

Zhao, S. Z., Wong, J. Y. H., Wu, Y., Choi, E. P. H., Wang, M. P., \& Lam, T. H. (2020b). Social distancing compliance under covid-19 pandemic and mental health impacts: A population-based study. International Journal of Environmental Research and Public Health, 17(18), 1-11. https://doi.org/10.3390/ijerph17186692

Publisher's Note Springer Nature remains neutral with regard to jurisdictional claims in published maps and institutional affiliations. 